\title{
Growth Response, Production, and Revenue Analysis of Hiyung Cayenne Pepper (Capsicum Frutescens L) with Dosage Application of Liquid Bokashi Fertilizer (Lbf) from Cattle Waste and Rice Straw
}

\author{
Mahdiati*, Danang Biyatmoko, Rizqi Puteri Mahyudin, Erma Agusliani \\ Department of Natural Resources and Environmental Management, Postgraduate Program, Lambung Mangkurat \\ University, Banjarbaru, 70714, Indonesia \\ *Correspondence: mahdiati.ati@gmail.com
}

Received: 26 October 2020; Accepted: 22 November 2020; Published: 7 December 2020

\begin{abstract}
The study aimed to (1) analyze the nutrient content of liquid bokashi fertilizer (LBF) derived from cattle waste and rice straw, (2) analyze the effect of liquid bokashi fertilizer dose on plant height, age of first flowering, and the number of fruits in the first harvest, the weight of the first fruit, and the weight of fresh fruit biomass. Analyzing revenue (income versus cost) and the feasibility of planting the Hiyung cayenne pepper by applying LBF at various dosage levels. The method used in this study was a Single Complete Randomized Design (CRD) with data analysis using ANOVA with further testing of Real Differences (LSD). B0 was control (without bokashi). B1 consisted of $125 \mathrm{ml}$ of LBF and water to dilute the solution up to $500 \mathrm{ml}$. B2 consisted of $250 \mathrm{ml}$ of LBF and water to dilute the solution up to $500 \mathrm{ml}$. B3 consisted of $375 \mathrm{ml}$ of LBF and $125 \mathrm{ml}$ of water. B4 consisted of $500 \mathrm{ml}$ of LBF. The results showed that the highest growth response $(69 \mathrm{~cm})$ occurred with the addition of $125 \mathrm{ml}$ of LBF, while the lowest growth occurred in the control (B0). In the first age, the most optimal flowering occurs in the B2 of 60.00 dap, and lowest in the control (B0) of 50.00 dap. The highest number of fruits was obtained from B2 of $170.00 \mathrm{~g}$, and the lowest was in B0 (control) of $94.00 \mathrm{~g}$. The average weight of the first fruit was found in B2 of $285.00 \mathrm{~g}$, and the lowest in B0 (control) of $126.00 \mathrm{~g}$. The highest weight of plant biomass was found in B2 of $405.00 \mathrm{~g}$, and the lowest was in B0 (control) of $177.75 \mathrm{~g}$. The highest revenue analysis and business feasibility were found in B2, namely Rp. 17.065/plant and the ratio of 4,96. The lowest revenue occurred in Control, which was Rp. 5.318,75 with a TR/TC value of 2.28. Based on the revenue analysis, B2 treatment produced the highest revenue and was the most feasible to be applied compared to other treatments.
\end{abstract}

Keywords: Cattle Waste, Growth Response, Hiyung Cayenne Pepper, Liquid Bokashi Fertilizer (LBF), Production and Revenue Analysis.

\section{Introduction}

Hiyung is one of the varieties of cayenne pepper in Indonesia and is a superior local variety in South Kalimantan (Kementan,2018). This cayenne pepper, developed by the farmer, has a high level of spiciness with the level of capsaicin reaching $94,500 \mathrm{ppm}$. In addition to its very spicy taste, Hiyung cayenne pepper also has a long shelf life (10-16 days at room temperature).

Maintenance of Hiyung cayenne pepper in general involves the replanting of dead young plants. Replanting should be conducted no later than 14 days after planting, so the plant growth is uniform. At 
the age of 20 days, the plants are stamped by removing the shoots that come out of the underarm leaves under the main branch (under branch V). Stakes are given at the time of planting or 14 days after planting so plants stand upright Jumar. (2004).

Preliminary tests showed that the material contained $0.08 \%$ nitrogen (N-Total), $0.06 \%$ phosphorus (P205), 0.08\% potassium (K), and 0.11\% Carbon (C). Liquid waste with nitrogen and organic carbon are the elements needed in the production of liquid bokashi fertilizer (LBF) and for plant growth and development Emma (2011).

Based on the previous description, it is necessary to investigate the dosage effect of liquid bokashi fertilizer (LBF) from cattle waste and rice straw on the growth response, production, and revenue analysis of Hiyung chili cayenne pepper (Capsicum frutescens l).

\section{Materials and Methods}

\section{Materials}

The materials used in this study were cattle waste, rice straw, brown sugar, bran, rice husk, EM4 activator liquid, and plant seeds of Hiyung chili pepper. The tools used were $30 \mathrm{ml}$ containers, stirrers, sacks, ropes, scales, gloves, masks, machetes, chopper tools, hoes, poly bags, balusters, spray bottles, ruler, measuring cups, watermarks, and plastic bottles. This research used a Completely Randomized Design (CRD) with a composition of compost treatment consisting of 4 treatments. Formulations for compost treatment are presented in Table 1.

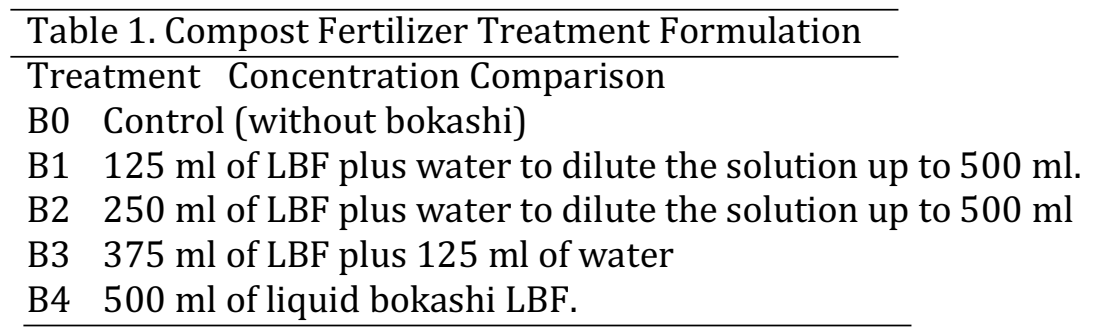

Source: Researcher and refer to the Modification of Subadriyo (2012)

Each treatment consisted of three replications, so there were twelve treatment units. Observation data were analyzed with ANOVA with the help of SPSS 19 at a significance level of $\alpha<0.05$. The test will be continued with the Least Significant Difference test (BNT) if a difference (significant effect) occurs.

\section{Nutrient Content in Liquid Bokashi Fertilizer (LBF)}

The nutrient content is an element contained in the material, both of which is soluble or can be absorbed by plants or insoluble or cannot be absorbed by plants.

Table 2. Nutrient Content of Bokashi Fertilizer (LBF)

\begin{tabular}{llcc}
\hline Nutrient & $\begin{array}{l}\text { Nutrient } \\
\text { Content (\%) }\end{array}$ & $\begin{array}{c}\text { Permentan } \\
(\%)\end{array}$ & $\begin{array}{c}\text { Bokashi' }^{2)} \\
(\%)\end{array}$ \\
\hline N (Nitrogen) & 1.08 & $3-6$ & 1.13 \\
P(Phosphorus) & 1.08 & $3-6$ & 0.60 \\
K (Potassium) & 1.06 & $3-6$ & 0.29 \\
C (Carbon) & 2.11 & Min 6 & 30.03 \\
\hline
\end{tabular}

Table 2 shows that liquid bokashi fertilizer contained 1.08\% N, 1.08\% P, 1.06\% K, 2.11\% C. The results of this nutrient analysis were lower than the liquid organic fertilizer content of the Permentan (Regulation of the Minister of Agriculture Republic of Indonesia) standard (2011) but almost similar to the results of Raharjo and Nur Ajijah (2007). In general, rice straw contains $0.4 \% \mathrm{~N}, 0.2 \% \mathrm{P}, 0.7 \% \mathrm{~K}$, and 40\% C (Tanaka and Tim Balitpa, 2001). High levels of C in liquid bokashi were caused by high carbon content in rice straw, which was the main raw material (Safitri, 2019).

\section{Development of Plant Height of Hiyung cayenne pepper}

Plant height is a growth indicator that is measured by the length of the plant stem. The ANOVA analysis showed that all treatments had no significant effect on plant height $(p>0.05)$ with a significant value of 0.000 , therefore $\mathrm{H} 0$ was rejected. It means that there are significant differences between the 
average values after treatment. This is presumably due to the difference in LBF concentrations so that the nutrient concentrations given are following the requirements of the Hiyung cayenne pepper plant. The main nutrient element in LBF, namely nitrogen $(\mathrm{N})$, plays an important role in the development of plant height. The height growth of the Hiyung cayenne pepper plant is presented in Figure 1.

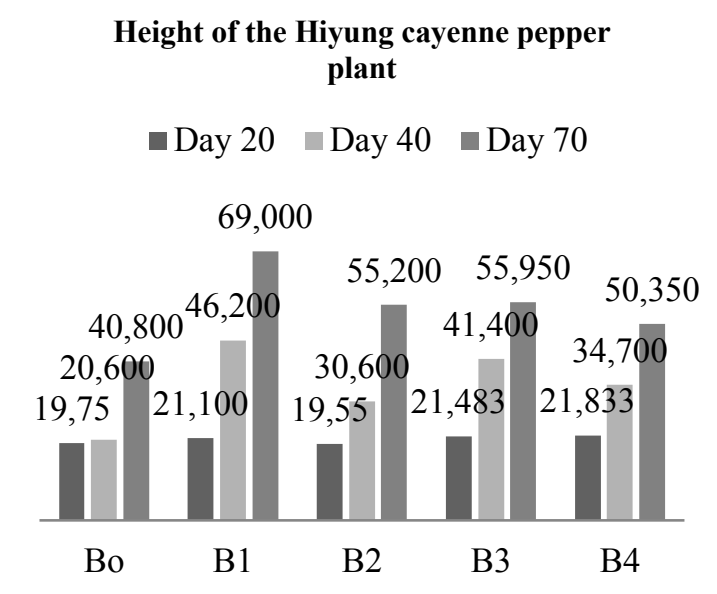

Figure 1. Growth of Plant Height

Figure 1 shows the increase that occurred in the growth of Hiyung cayenne pepper from day 20 to day 70 . On the 20th day, no significant growth was seen, but after the 70th day, the height of the Hiyung cayenne pepper plant was seen. Marliah (2003) states that good growth in chili plants indicates an adequate or optimal amount of macro and micronutrient needs. The same opinion is also stated, that the availability of $\mathrm{N}, \mathrm{P}$, and $\mathrm{K}$ can stimulate vegetative growth of plants such as stems, roots, leaves, and branches. Nitrogen $(\mathrm{N})$ is the most determining factor for plant height because this element is needed in the vegetative phase Alabi (2006).

The first age of flowering

The first age of flowering is the stage of reaching the fertilization phase. In this phase, it can also be seen that the flowering rate determines the level of plant fertility and is obtained from nutrient enrichment both from the planting media and from outside (liquid waste).

The ANOVA analysis showed that all treatments had no significant effect on the age of first flowering ( $p>0.05)$ with a significance value of 0.647 , hence H0 was accepted. It means that there is no significant difference between the average value after treatment. It shows that the fertilizer dosage does not have a significant effect on the flowering age of the Hiyung cayenne pepper plants.

The first age of the flowering of Hiyung cayenne pepper plant

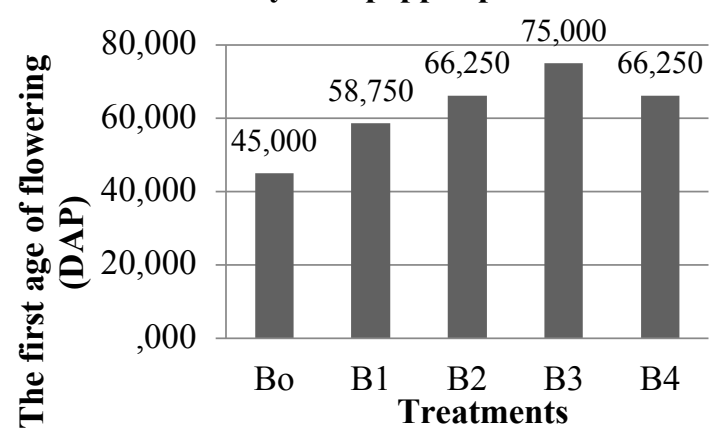

Figure 2. First Age of Flowering on a Hiyung cayenne pepper Plant

Figure 2 shows that the average age of early flowering is longer than the standard description of the Hiyung cayenne pepper varieties reported by BPTP South Kalimantan (2018), with the age of flowering starting at the age range of 45 - 50 DAP. This difference is believed due to differences in weather during planting. The weather was very hot during the planting, causing the soil to dry out quickly, hence the plants were less developed. Furthermore, the difference in fertilizer applied also affects. In this study, only LBF fertilizers were given without the addition of inorganic fertilizers such as NPK, Urea, TSP, or KCl. As a result, the nutrients needed by Hiyung chili plants were incomplete. 
The number of Hiyung cayenne pepper fruits

The number of fruits produced is the ability of a Hiyung cayenne pepper plant to absorb nutrients and adapt to the environment. Plants are said to grow well if the number of fruits produced is high.

The ANOVA analysis showed that all treatments had no significant effect on the first flowering age ( $p>0.05$ ) with a significance value of 0.345 , then $\mathrm{H} 0$ was accepted. It means that there is no significant difference between the average value after treatment. It shows that the fertilizer dosage has a significant effect on the number of fruits produced by the Hiyung cayenne pepper plant

The number of Hiyung cayenne peppers fruits

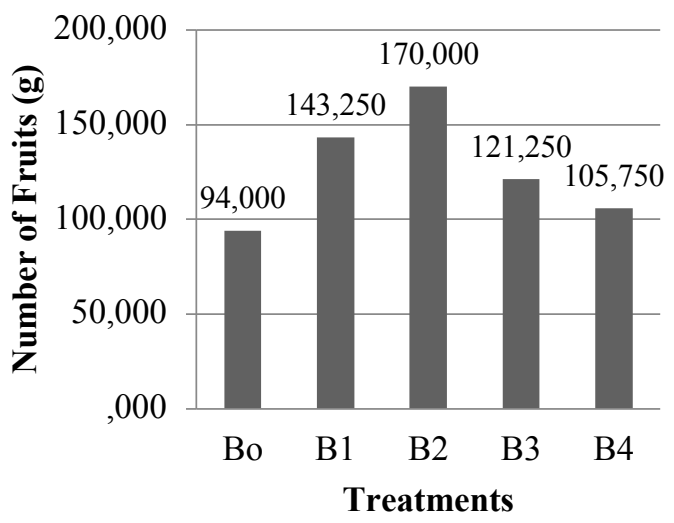

Figure 3. Number of Hiyung cayenne pepper fruits

Figure 3 shows that the LBF application can increase the flowering and fruit formation process. The highest number of fruits produced by treatment B2 (250 ml dose LBF/500 ml water) with 170 fruits/plant, while the lowest from treatment B0 (control) with 94 fruits/plants. Quadratic application of liquid bokashi fertilizer can increase fruit production up to a dose of $250 \mathrm{ml} / 500 \mathrm{ml}$ of water in B2 treatment. After that, the increase will cause a decrease in fruits production to 105 fruits/plants. Therefore, the optimal dosage of LBF is up to $250 \mathrm{ml} / 500 \mathrm{ml}$ of water (1:2), which has a positive impact on the amount of fruit produced.

\section{Weight of the Hiyung cayenne pepper fruits (g/plant)}

Fruit weight is the weight of the fruit produced after the harvest period. Fruit weight can be influenced by the amount of nutrient uptake by plants. The weight of the fruit will determine the level of environmental adaptation, the media, and nutrient absorption both from within the growing media and outside Alhrout (2017).

The ANOVA analysis showed that all treatments had no significant effect on the age of first flowering ( $p>0.05$ ) with a significance value of 0.000 , then $\mathrm{H} 0$ was rejected. It means that there are significant differences between the average values after treatment.

Plant Biomass

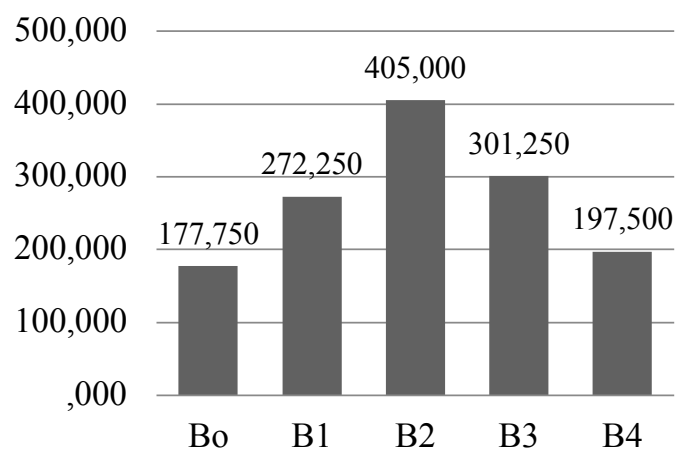

Figure 4. Plant biomass of the Hiyung cayenne pepper

Figure 4 shows that the weight of the Hiyung cayenne pepper is highly positively correlated with the total number of fruit produced. Treatment B2 with the LBF dose of $250 \mathrm{ml} / 500$ water produced 
the highest number of fruits of all treatments (170 chilies/plant) so that it also produced the highest fruit weight, $285 \mathrm{~g} /$ plant. Consequently, nutrients needed by the Hiyung cayenne pepper plants is less complete.

\section{Revenue Analysis and Feasibility of the Hiyung cayenne pepper Cultivation}

Revenue analysis is intended to determine the amount of income from the cultivation of the Hiyung cayenne pepper per plant from one harvest $(\pi)$. The revenue analysis is calculated from the difference between total revenue (TR) and total costs used (TC) Nuraida, (2015).

Based on the revenue analysis, treatment B2 produced income $(\pi)$ of 17.065 ,- IDR/plant, while based on feasibility analysis, B2 treatment had a TR/TC ratio of 4.96.

\section{Conclusions}

The conclusions of the studies are, first, The liquid bokashi fertilizer (LBF) produced contained $1.08 \% \mathrm{~N}, 1.08 \% \mathrm{P}, 1.06 \% \mathrm{~K}$, and $2.11 \% \mathrm{C}$. The LBF nutrient content was lower than the Permentan organic fertilizer standard, but more or less the same as bokashi in general. Second, LBF dosage of 250 $\mathrm{ml} / 500$ water (B2) in the Hiyung cayenne pepper plant produced the highest productivity with flowering age of 52.5 days, 170 fruits, fruit weight of $285 \mathrm{~g} /$ plant, and biomass weight of $405 \mathrm{~g} / \mathrm{plant}$ while plant height was not significantly different. Third, The highest revenue was generated by liquid bokashi fertilizer $250 \mathrm{ml} / 500$ water (B2) with an income of 17.065 IDR/plant, TR of 21,375 IDR/plant, TC of 4.310 IDR/plant, and farm feasibility with TR/TC ratio of 4,96.

\section{References}

Alabi, D. A. 2006. Effect of Fertilizer Phosphorus and Poultry Droppings Treatments on Growth and Nutrient Components of Pepper (Capsicum annum L.). African Journal of Biotechnology.5(8):671-677.

Alhrout, H. 2017. Response of Growth and Yield Components of Sweet Pepper to Tow Different Kinds of Fertilizers under Green House Conditions in Jordan. Journal of Agricultural Science.9(10):265-272. DOI: 10.5539/jas.Vol 9 (10) p 265.

BPTP South Kalimantan, 2018. Ministry of Agriculture Hiyung Chili, South Kalimantan local SDG. www.litbang.pertanian.go.id

Tapin Regency Agriculture Office, 2018. Book SOP on cultivating Hiyung Tapin Chili.

Jumar. 2004. Methods of Making Organic Fertilizers with the Help of Microbes with the Help of Decomposers. Department of Pests and Diseases, Faculty of Agriculture, Agricultural University. Banjarbaru

Emma S. (2011). Utilization of Organic Crop Waste.

Marliah, A., Nurhayati, \& Riana, R. (2013). Effect of Varieties and Concentration of Compound Fertilizer on Growth and Yield of Flower Cabbage (Brassica oleracea L.). Floratek, 8 (2), 118-126.

Nuraida, 2015. Analysis of Revenue and Feasibility of Farming Rawit Chili in Potoya Village, Dolo District, Sigi Regency.

Regulation of the Minister of Agriculture Number 70 / Permentan / SR.140 / 10/2011 Tenteng for Organic Fertilizer, Biological Fertilizer and Soil Improvement

Safitri, R. D. 2019. Performance of Compost from Waterthyme (Hydrilla Verticillata) in Bok Choy Growth (Brassica chinensia) 